\title{
Ensinando comportamento criativo: uma revisão em três periódicos da Análise do Comportamento
}

\author{
Emerson Ferreira da Costa Leite \\ Fátima Regina Pires de Assis' \\ Pontifícia Universidade Católica de São Paulo - SP - Brasil
}

\begin{abstract}
Resumo: Desde Skinner, autores da Análise do Comportamento contribuíram para descrever e explicar o fazer criativo. Objetivando avaliar a produção sobre o tema, foi realizada revisão de uma amostra de $5 \mathrm{I}$ artigos extraída de 280 encontrados utilizando o termo de busca "creative" em três periódicos (The Behavior Analyst, Journal of the Experimental Analysis of Behavior e Journal of Applied Behavior Analysis), desde a primeira publicação dos mesmos, até o ano de 2015. Os resultados evidenciaram que diversos conceitos e procedimentos estão envolvidos ao referir-se ao comportamento criativo na perspectiva analítico-comportamental, não existindo uma linha de pesquisa unificada sobre o tema. A despeito disso, tecnologias para produzir respostas novas estão disponíveis, destacando-se o reforçamento direto de variabilidade. Foi avaliado se os resultados obtidos com esses procedimentos atendem ou não às exigências skinnerianas para considerarmos criativo um comportamento. $O$ procedimento de validação social, utilizado nas pesquisas mais antigas da amostra, parece ser uma alternativa metodológica apropriada para essa investigação.
\end{abstract}

Palavras-chave: criatividade; comportamento criativo; variabilidade; revisão de literatura; análise do comportamento.

\section{TEACHING CREATIVE BEHAVIOR: A REVIEW IN THREE JOURNALS OF BEHAVIOR} ANALYSIS

\begin{abstract}
Since Skinner, Behavior Analysis's authors contributed to describe and explain the creative doing. To evaluate the literature on the subject, a review of a $5 \mathrm{I}$ articles sample extracted of 280 found using the search term "creative" was realized in three journals (The Behavior Analyst, Journal of the Experimental Analysis of Behavior and Journal of Applied Behavior Analysis), since the first publication until the year 2015. The results showed that various concepts and procedures are involved when referring to creative behavior in behavior analytic perspective, there being not a unified research area on the subject. Despite this, technologies to produce new responses are available, being distinguished the direct reinforcement of vary. Was evaluated if the results obtained with these procedures complies or not to Skinner's requirements to consider creative behavior. The social validation procedure used in earlier studies of the sample appears to be an appropriate alternative methodology for this research.
\end{abstract}

Keywords: creativity; creative behavior; variability; literature review; behavior analysis.

\section{ENSEÑANDO COMPORTAMIENTO CREATIVO: UNA REVISIÓN EN TRES REVISTAS DE ANÁLISIS DEL COMPORTAMIENTO}

Resumen: Desde Skinner, autores del análisis de comportamiento contribuyeron a describir y explicar el hacer creativo. Para evaluar la literatura sobre el tema, la revisión

1 Endereço para correspondência: Fátima Regina Pires de Assis, Pontifícia Universidade Católica de São Paulo, Rua Monte Alegre, 948, Perdizes - São Paulo - SP, Brasil. CEP: 05014-901. E-mail: frassis@pucsp.br. 
se realizó sobre una muestra de $5 \mathrm{I}$ artículos tomada de 280 encontrados con el término de búsqueda "creative" de cada tres revistas (The Behavior Analyst, Journal of the Experimental Analysis of Behavior and Journal of Applied Behavior Analysis), desde la primera publicación de las mismas, hasta el año 2015. Los resultados mostraron que diversos conceptos y procedimientos están involucrados cuando se refiere a la conducta creativa en la perspectiva analítica del comportamiento, no habiendo un área de investigación unificada sobre el tema. A pesar de esto, las tecnologías para producir nuevas conductas están disponibles, se destacando el refuerzo directo de la variabilidad. Se evaluó si los resultados obtenidos con estos procedimientos cumplen o no con los requisitos de Skinner para considerar la conducta creativa. El procedimiento de validación social utilizado en estudios anteriores de la muestra parece ser una metodología alternativa adecuada para esta investigación.

Palabras clave: creatividad; comportamiento creativo; variabilidad; revisión de literatura; análisis del comportamiento.

O estudo do comportamento criativo na abordagem behaviorista radical não é matéria recente. Segundo Epstein (1991), contribuições da abordagem para a definição e explicação da criatividade foram apresentadas por Skinner em diferentes textos ao longo de sua obra (Skinner, 1956, 1957, 1970, 1966, 1968 e 1981). Na história da abordagem, o conceito sofreu transformações. Nos anos 1980, por exemplo, alguns autores defendiam que criatividade envolvia o controle do responder por múltiplos estímulos (Sloane, Endo, \& Della Piana, 1980), outros salientavam que criatividade implicava no desconhecimento das variáveis de controle do responder (Epstein, 1980). Apesar de atualmente existirem avanços mais estabelecidos nessas definições (Barbosa, 2003; Bandini \& de Rose, 2006; Souza \& Kubo, 2010), ainda não se pode afirmar com segurança sobre a existência de consenso na área. Esses fatos revelam a necessidade de estudar o tema em uma perspectiva comportamental.

Considerando as contribuições de diferentes autores e revisões sobre tais contribuições, apontaremos a seguir quatro elementos que estão envolvidos em uma definição comportamental de criatividade.

O primeiro elemento corresponde à delimitação do fenômeno em questão como um fenômeno comportamental (Skinner, 1972). Em outras palavras, criatividade é comportamento. Tal delimitação tem implicações teóricas, metodológicas e práticas.

Do ponto de vista teórico, os analistas do comportamento têm como ponto de partida que o comportamento de "criar" é determinado pelas mesmas leis de outros operantes quaisquer, sendo, portanto, modelado e mantido pelas consequências que produz. Por essa razão, tal comportamento pode ser explicado pelos conceitos da abordagem comportamental, tornando desnecessário o apelo a variáveis explicativas de dimensões não físicas. Do ponto de vista metodológico, nenhum "procedimento especial", diferente daqueles utilizados pela abordagem, é necessário para o estudo deste comportamento. Finalmente, do ponto de vista prático, uma vez que é determinado pelas condições ambientais nas quais o indivíduo responde, o "criar" pode ser ensinado a qualquer pessoa de maneira planejada.

Planejar o criar, entretanto, não se trata de encontrar uma resposta original ou criativa e ensiná-la a alguém, o que seria improcedente com uma definição de criati- 
vidade, mas sim de provocar perturbações e encorajar mudanças que tornem mais provável o surgimento de comportamentos criativos, por meio do planejamento de um arranjo fortuito de contingências (Skinner, 1972).

O segundo elemento é o de que o modelo de causalidade adotado pelos analistas do comportamento - o modelo skinneriano de seleção por consequências - tem como aspecto inerente a variabilidade. Assim como as mutações das espécies são condições para a seleção do ambiente natural, as variações no comportamento são condições para a seleção do responder pelas consequências que produz. Nesse sentido, em um nível filosófico, o modelo behaviorista radical está apto a explicar realizações originais, como destacou Skinner (1972), em um sentido similar àquele empregado por Darwin no título de A Origem das Espécies (Laurenti, 2009). Tomando esta posição, Skinner indica que comportamento criativo é fruto de um arranjo fortuito de contingências, geralmente, acidentais, mas que podem ser programadas.

O terceiro elemento nesta discussão refere-se ao grau de novidade necessário para considerarmos um comportamento criativo. Bandini e de Rose (2006) alertam que a rigor uma resposta emitida é sempre nova, uma vez que nunca é igual à outra resposta, ainda que pertencentes à mesma classe de respostas. De maneira menos específica, toda resposta emitida pela primeira vez é nova em seu repertório idiossincrático. Modelagem, portanto, sempre gera comportamentos novos. Mas não estaríamos propensos a chamar de criativo um comportamento semelhante ao que apresentamos há alguns minutos atrás só porque não é rigorosamente idêntico àquele; também não diríamos que fomos criativos quando calçamos sozinhos os sapatos pela primeira vez. Considerando esse ponto, Skinner (1968) definiu como um dos critérios para chamarmos o comportamento de criativo, o de que este fosse novo em um sentido especial, não bastando ser meramente diferente. Tratando de tal proposição skinneriana, Bandini e de Rose (2006) apontaram que o comportamento deve diferir de todas as respostas emitidas pelos indivíduos da cultura. Para designar esse grau especial de novidade, Skinner reservou o adjetivo original.

Esse critério coloca-nos diante da discussão do quarto aspecto da definição de criatividade: o de que original, como afirmam Skinner (1968), Hunziker (2006) e Bandini e de Rose (2006), não descreve um comportamento, mas apenas indica a existência de um referente de comparação. Em outras palavras, o comportamento é original em determinada comunidade, ou seja, depende do contexto de análise.

Bandini e De Rose (2006, p. 57) ressaltam, entretanto, que a comunidade não precisa ser entendida como um conceito rígido, podendo sofrer ampliações e reduções, não sendo necessária a ignorância completa de qualquer comunidade àquele comportamento para considerá-lo criativo. Nas palavras desses autores, "qualquer critério utilizado aqui como um divisor entre comportamento novo e um comportamento criativo é arbitrário em alguma medida".

Tais considerações sobre o grau de originalidade para considerarmos um comportamento criativo e, em decorrência, sobre o contexto de análise ou a comunidade 
arbitrariamente definida em que o comportamento é apresentado, relacionam-se diretamente ao critério de reforçamento desse comportamento.

Em revisão sobre o tema da criatividade, Souza e Kubo (2010) apresentaram uma síntese da definição de comportamento criativo a partir da unidade básica de análise do comportamento, a tríplice contingência. Um dos termos da tríplice contingência refere-se às consequências do comportamento, no presente caso, do comportamento criativo. A revisão de literatura empreendida por esses autores apontou que para ser criativo o comportamento tem de ser útil, relevante, ter importância prática no contexto em que ocorre, ainda que tal utilidade seja, por exemplo, estética.

Em outras palavras, envolve reforçamento para o indivíduo e/ou para sua comunidade. Isso parece implicar que, em grande medida, a avaliação do grau de originalidade do comportamento para que seja reforçado como "criativo" é empreendida pela própria comunidade que o reforça.

Considerando a análise de Souza e Kubo (2010), que inclui também os estímulos antecedentes da tríplice contingência para descrever comportamento criativo, concluímos que esse pode ser definido de, pelo menos, duas maneiras: uma resposta original sendo emitida em contexto conhecido, e produzindo reforço para o indivíduo e/ ou para sua comunidade; e uma resposta conhecida sendo emitida em contexto novo, e produzindo reforço para o indivíduo e/ou sua comunidade.

Terceira possível definição para comportamento criativo é aquela oferecida por Skinner (1953) ao abordar o comportamento de "ter uma ideia" como solucionadora de um problema, exatamente a produção de uma resposta original. Nesta definição, comportamento criativo envolveria respostas manipulativas precorrentes, produzindo as condições fortuitas nas quais respostas originais tornam-se prováveis de serem emitidas e, por sua vez, produzirem reforços para o indivíduo e/ou sua comunidade, assemelhando-se ao que se tem chamado de autocontrole (Skinner, 1968), no sentido de que este comportamento também envolve respostas precorrentes produzindo as variáveis que alteram a probabilidade de outras respostas (Murari \& Henklain, 2013). No entanto, criar diferencia-se de autocontrole pelo fato de esse não envolver respostas necessariamente originais.

Além dos aspectos citados, o estudo comportamental da criatividade parece envolver muitos processos básicos descritos pela pesquisa experimental do laboratório, tais como o processo de interconexão de repertórios na solução de problemas (Epstein 1996; Delage \& Carvalho Neto, 2006; Murari \& Henklain, 2013), o processo de equivalência de estímulos (Sidman, 1989 apud Sério, Andery, Gioia, \& Micheletto, 2002), e o que se tem observado nos estudos de variabilidade reforçada (Pryor, Haag, \& O'Reilly, 1969; Neuringer, 2002; Abreu-Rodrigues, 2005; Murari \& Henklain, 2013; Figueiredo, 2014). Além desses processos, Shahan e Chase (2002) apontam outros, tais como: discriminação e generalização, extensão de tatos, formação de conceitos, abstração, comportamento autoclítico, variações nas consequências, ressurgência, entre outros, o que atesta ainda mais a complexidade do fenômeno em análise. 
A despeito das dificuldades na definição teórica do comportamento criativo e da complexidade implicada em seu estudo experimental, trabalhos práticos têm sido realizados no sentido de aumentar a probabilidade de respostas criativas em diferentes contextos, como indica revisão histórica realizada por Winston e Baker (1985), possibilidade que havia sido defendida por Epstein (1980). Tal aplicação da ciência comportamental, segundo Skinner (1968), tem relevância prática para a cultura, no sentido de que uma comunidade que encoraja comportamento incomum em seus indivíduos tem mais chances de ter seus problemas resolvidos, especialmente quando se trata de problemas para os quais ninguém ainda encontrou solução.

Winston e Baker (1985) realizaram uma revisão de 20 estudos analítico-comportamentais entre 1958 e 1985. Consideraram, entre outras, as seguintes categorias de análise: número de participantes/sujeitos; modalidade de resposta; procedimento de intervenção; medidas de criatividade; resultados; delineamento experimental; e medidas de validação social. Alguns dos aspectos discutidos na revisão foram a insuficiência de novidade para caracterizar criatividade e o uso da validação social como procedimento relevante nos estudos como forma de abarcar a parte seletiva do processo criativo.

Dadas a complexidade da pesquisa em criatividade e a importância prática deste conhecimento para a cultura, o estudo histórico da produção a respeito do comportamento criativo constitui um meio importante de identificar os avanços e desafios para a abordagem nessa área e, quando possível, analisar as variáveis que controlam o comportamento de produzir ciência dos analistas do comportamento que estudaram o tema (Andery, Micheletto, \& Sério, 2000).

Tal investigação é um passo na direção de elaborar novas propostas de estudo do comportamento criativo e de intervenções interessadas em produzir esse comportamento. Também pode constituir condição para aumentar a probabilidade de que o analista do comportamento passe a intervir em diferentes contextos de atuação ou de diferentes formas em contextos já conquistados. A necessidade de pessoas que se comportem criativamente, seja na clínica, seja no contexto organizacional/empresarial, seja na educação, além do contexto de produção artística, é claramente apresentada no mundo contemporâneo. A sistematização proposta neste trabalho constitui um passo a mais no sentido de subsidiar a prática do analista do comportamento nesses casos.

Secundariamente, ao considerarmos a lista de críticas errôneas comumente feitas ao Behaviorismo Radical, enumeradas por Skinner (1974), sendo duas delas diretamente relacionadas ao pensamento bastante difundido de que tal filosofia não pode explicar a criatividade, avanços na aplicação na área do comportamento criativo permitirão que tais críticas, que já foram refutadas teoricamente, sejam progressivamente refutadas também com dados empíricos.

O objetivo da presente pesquisa foi, portanto, avaliar a produção de trabalhos analítico-comportamentais teóricos e empíricos sobre comportamento criativo em três 
periódicos internacionais, analisando a frequência de publicações em cada periódico, caracterizando tais trabalhos na maneira como tratam a questão da criatividade, identificando processos básicos dos quais lançam mão para embasar suas pesquisas, participantes, modalidade de resposta, setting e observando as medidas de criatividade comumente utilizadas.

\section{Método}

\section{Periódicos selecionados}

Foram analisadas todas as publicações encontradas em três periódicos internacionais de Análise do Comportamento: Journal of the Experimental Analysis of Behavior (Jeab), Journal of Applied Behavior Analysis (Jaba) e The Behavior Analyst (TBA), por serem respectivamente referências na pesquisa básica, aplicada e teórica/conceitual. Os periódicos foram analisados desde a sua primeira publicação até o ano de 2015.

\section{Definição do termo de busca}

Inicialmente, diferentes palavras-chave que poderiam estar relacionadas ao comportamento criativo foram utilizadas como termos de busca nos três periódicos selecionados. São elas: creativity (criatividade) create (criar), creative (criativo), novelty (novidade), novel (novo), originality (originalidade), original (original), variability (variabilidade), diversity (diversidade), artistic (artístico) e art (arte).

Somando os dados dos três periódicos, os resultados obtidos indicaram um número maior de artigos para os termos relacionados, mas não específicos ao objetivo do estudo (original, 2103 artigos, variability, 1994 e novel, 1345), quando comparados aos termos de busca específicos (creativity, 164, creative, 280 e create, 614). Os termos também não específicos novelty, originality e diversity apresentaram números próximos ou maiores quando comparados aos termos diretamente relacionados ao tema de revisão, enquanto os termos artistic e art somaram em conjunto 397 artigos. Esses dados apontam na direção de tendências na produção da abordagem, com menor uso de termos como criatividade e criativo, foco do presente trabalho.

Entre os termos especificamente relacionados ao tema de pesquisa (criatividade), optou-se inicialmente por aquele termo de busca que constasse de um número intermediário de artigos (creative com 280 artigos). Posteriormente aos procedimentos de inclusão e exclusão, constatou-se que os artigos encontrados com o termo creativity (164) estavam incluídos na lista obtida com o termo creative. Por outro lado, muitos dos artigos encontrados com creative foram eliminados pelos critérios de exclusão, o que nos levou a concluir que o uso do termo create (614 artigos) provavelmente não adicionaria artigos na amostra analisada e implicaria em ainda mais exclusões.

Todos os artigos coletados na busca foram salvos em formato digital e submetidos à fase seguinte do procedimento. Depois disso, considerando os critérios apontados no parágrafo anterior, o termo de busca adotado foi creative. 


\section{Critérios de inclusão e exclusão para a amostra}

Diante de um grande número de artigos, nem sempre diretamente relacionados ao tema, o título e resumo de todos os artigos encontrados a partir do termo de busca creative foram lidos e, a partir desta leitura, elaboraram-se critérios de inclusão e exclusão dos mesmos na amostra a ser analisada.

Os artigos foram incluídos na amostra sempre que atenderam a pelo menos um dos seguintes critérios:

1. conter em seu título, resumo ou palavras-chave algum termo derivado da partícula verbal creat;

2. conter em seu corpo duas ou mais vezes termo derivado da partícula verbal creat;

3. conter em suas referências estudos cujo título, periódico ou livro no qual foi publicado, contivessem termo derivado da partícula creat.

O uso desta partícula está relacionado ao fato de, em inglês, existirem tanto termos em que essa partícula é seguida pela letra "i" (como no substantivo creativity e no adjetivo creative) quanto termos em que é seguida pela letra "e" (como no verbo create).

Aplicaram-se, então, aos artigos incluídos pelos critérios 1 a 3, os critérios de exclusão, elaborados a partir de uma análise caso a caso dos artigos que apresentavam problemas para a amostragem por não estarem claramente relacionados ao tema revisado. Foram estes:

1. artigos em que creative estivesse sendo usado como adjetivo para pesquisadores, seus procedimentos e os efeitos obtidos com suas intervenções (quando o adjetivo era usado para designar participantes/sujeitos, seus atos, ou efeitos de seus atos, o texto não era excluído);

2. artigos em que criar estivesse sendo usado como simples sinônimo de "fazer", "produzir", "programar", "planejar" etc. fora do contexto da criatividade;

3. artigos em que criatividade como fenômeno ou estudos sobre criatividade fossem citados apenas como exemplo em artigos que abordam outros temas não relacionados diretamente ao comportamento criativo;

4. artigos em que a partícula creat constituísse o nome de um instrumento ou procedimento.

Os critérios de inclusão e exclusão dos artigos levaram a uma amostra final de 51 artigos: 17 no Jaba, 18 no Jeab e 16 no TBA, extraída de 79, 89 e 112 artigos dos respectivos periódicos. Os critérios de inclusão foram responsáveis por descartar 32 (Jaba), 30 (Jeab) e 39 (TBA) artigos da amostra, enquanto os critérios de exclusão significaram a retirada de mais 30 (Jaba), 41 (Jeab) e 57 (TBA) artigos. 


\section{Procedimentos de análise}

Uma vez selecionados, os 51 artigos da amostra foram catalogados a partir de categorias relativas aos dados básicos de identificação da referência (título, autor(es), ano, filiação e periódico em que foi publicado), e aspectos teórico-metodológicos (sujeitos/participantes, procedimento utilizado, principal conceito do artigo, principais variáveis manipuladas e medida de criatividade, quando possível). Algumas das categorias foram empregadas somente à pesquisa empírica (básica e aplicada) por não serem adequadas aos artigos teóricos.

Para tal, foram lidos títulos, resumos, palavras-chave e, sempre que necessário, introdução, método e figuras. Foi usada a ferramenta de busca de palavras utilizando as teclas Ctrl+F para identificar características procuradas nos textos, e sempre que um texto ocasionava dúvidas em um dos autores, o outro autor analisava o mesmo texto para corroborar ou alterar a decisão do primeiro.

Utilizaram-se como critérios para considerar uma categoria relevante: 1. categorias básicas de identificação do texto; 2. aspectos teórico-metodológicos dos trabalhos pertencentes à amostra; e 3. categorias usadas em uma revisão anterior no mesmo tema por Winston e Baker (1985).

\section{Resultados e discussão}

Apresentamos a seguir os principais resultados obtidos na revisão realizada com os 51 artigos considerados para a análise, sendo 17 no Jaba, 18 no Jeab e 16 no TBA que possibilitaram a seguinte caracterização da produção sobre o tema em análise.

O Gráfico 1 apresenta curvas acumuladas das publicações que constituem a amostra desde a primeira aparição em cada periódico analisado, considerando que o ano de início de cada um dos três periódicos foi: 1958, Jeab; 1968, Jaba e 1978, TBA. Quanto ao Jeab, a análise iniciou em 1969 porque este foi o ano de publicação do artigo mais antigo encontrado nesse jornal.

Analisando o total de produções, podemos observar que as publicações se mantêm crescentes ao longo do tempo com pausas esporádicas. As pausas observadas são relativas a períodos em que nenhum dos três periódicos analisados publicou sobre comportamento criativo, tal como ocorreu entre 1985 e 1988 e de 2006 a 2009. Quanto aos períodos de maior publicação, notamos os períodos de 1972 a 1980, de 1988 a 1994, 2001 a 2006 e, finalmente, de 2009 a 2012. O desenvolvimento nos estudos de variabilidade reforçada no final dos anos 1980 e início dos anos 1990 talvez possa estar relacionado à maior inclinação da curva de produção a partir desse mesmo período.

No entanto, ao atentarmos às publicações de cada periódico, notamos que o total de publicações foi muito semelhante, mas com diferenças nos períodos de publicação. Observamos que o período de maior frequência nas publicações, 1972 a 1980 deveu-se notadamente à produção do Java. De 1979 a 1992, a situação se inverteu: Jaba permaneceu sem publicar artigos até 1993, enquanto Jeab e TBA apresentaram alguma 
produção até 1985, sendo que nos três anos seguintes não foram identificadas publicações em alguma delas. Isto indica uma alternância no tipo de pesquisa realizada, tal como podemos identificar nos períodos de maior produção já citados, uma vez que no Jaba $90 \%$ das pesquisas analisadas são aplicadas e $10 \%$ teóricas, no Jeab $90 \%$ são básicas e 10/\% teóricas e, finalmente, no TBA 90\% são teóricas e 10\% históricas. Logo, inicialmente, há maior preocupação com a pesquisa da aplicação, seguida de desenvolvimentos na pesquisa básica e teórica. O fim da curva indica uma diminuição atual na produção de pesquisa aplicada em comportamento criativo.

\section{Gráfico I. Frequência acumulada de textos da amostra publicados por ano nos três periódicos analisados}

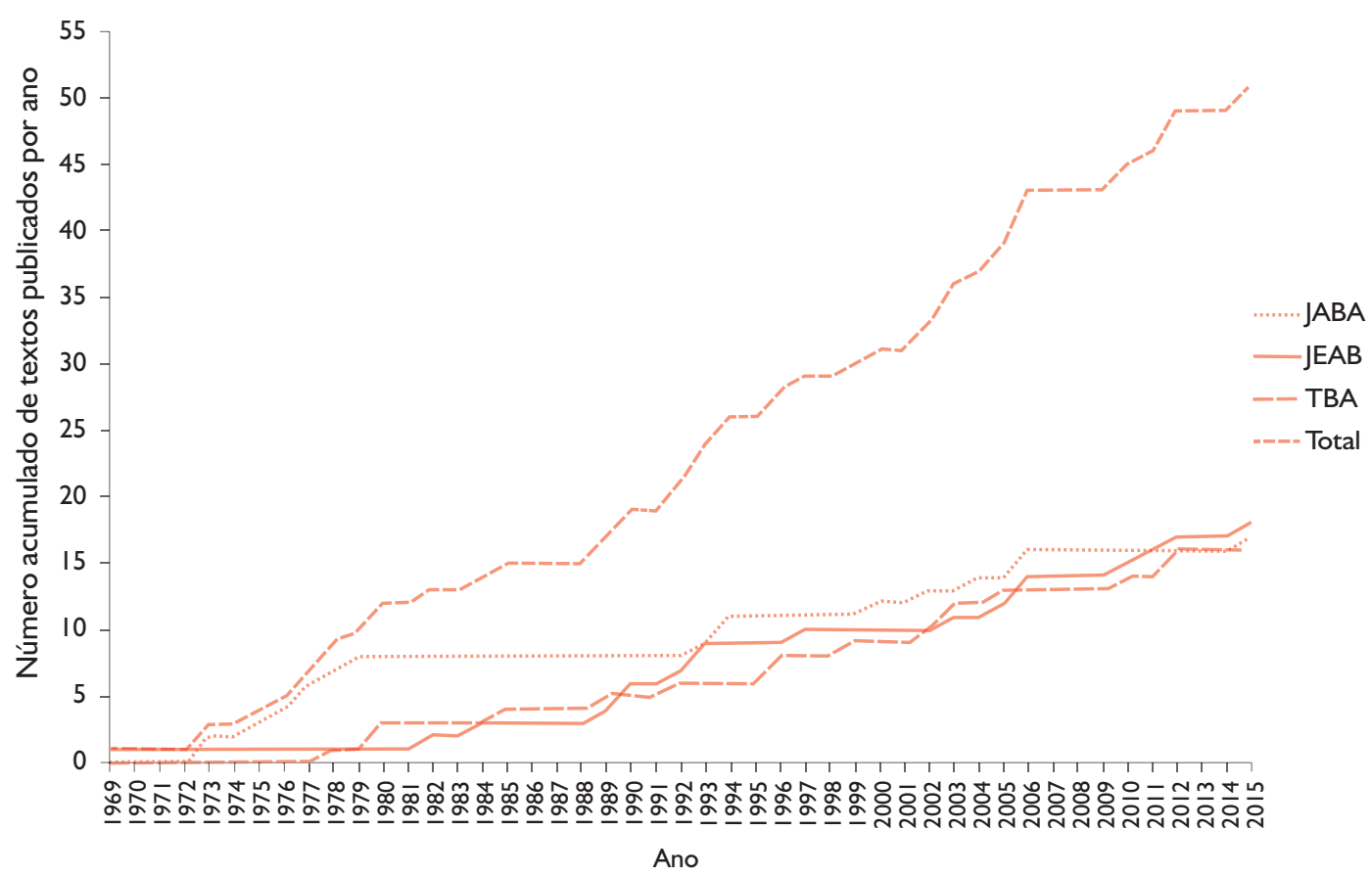

Fonte: Elaborado pelos autores.

O Gráfico 2 apresenta os termos/conceitos que ocorreram em $25 \%$ ou mais dos estudos de pelo menos um periódico analisado. Tais termos foram categorizados considerando a palavra que mais frequentemente os autores usaram para se referirem ao comportamento estudado (no título, resumo, texto introdutório ou de discussão, método, tabelas e gráficos). Como pode ser observado, apenas os termos "variabilidade", "novidade do responder" e "criatividade" atingiram esse critério. A análise dos dados indica que o tema "criatividade" foi identificado apenas no TBA, $25 \%$ da amostra da revista, "novidade do responder" foi mais frequente no Jaba, em $29,4 \%$ da amostra e, 
finalmente, "variabilidade" foi mais identificado no periódico Jeab, 61,1\% de sua amostra. Notamos também que o TBA publicou artigos que usaram os três termos analisados, enquanto Jaba e Jeab publicaram artigos apenas com os termos "novidade do responder" e "variabilidade", sendo que a distribuição é mais equitativa no Jaba e mais discrepante no Jeab. Esses dados parecem indicar que, acompanhando a especialização dos periódicos, a forma como os autores se comportam diante do fenômeno estudado também tendeu a se especializar.

\section{Gráfico 2. Percentual de trabalhos em cada periódico que tinham como tema/conceito central: criatividade, novidade do responder, e variabilidade}

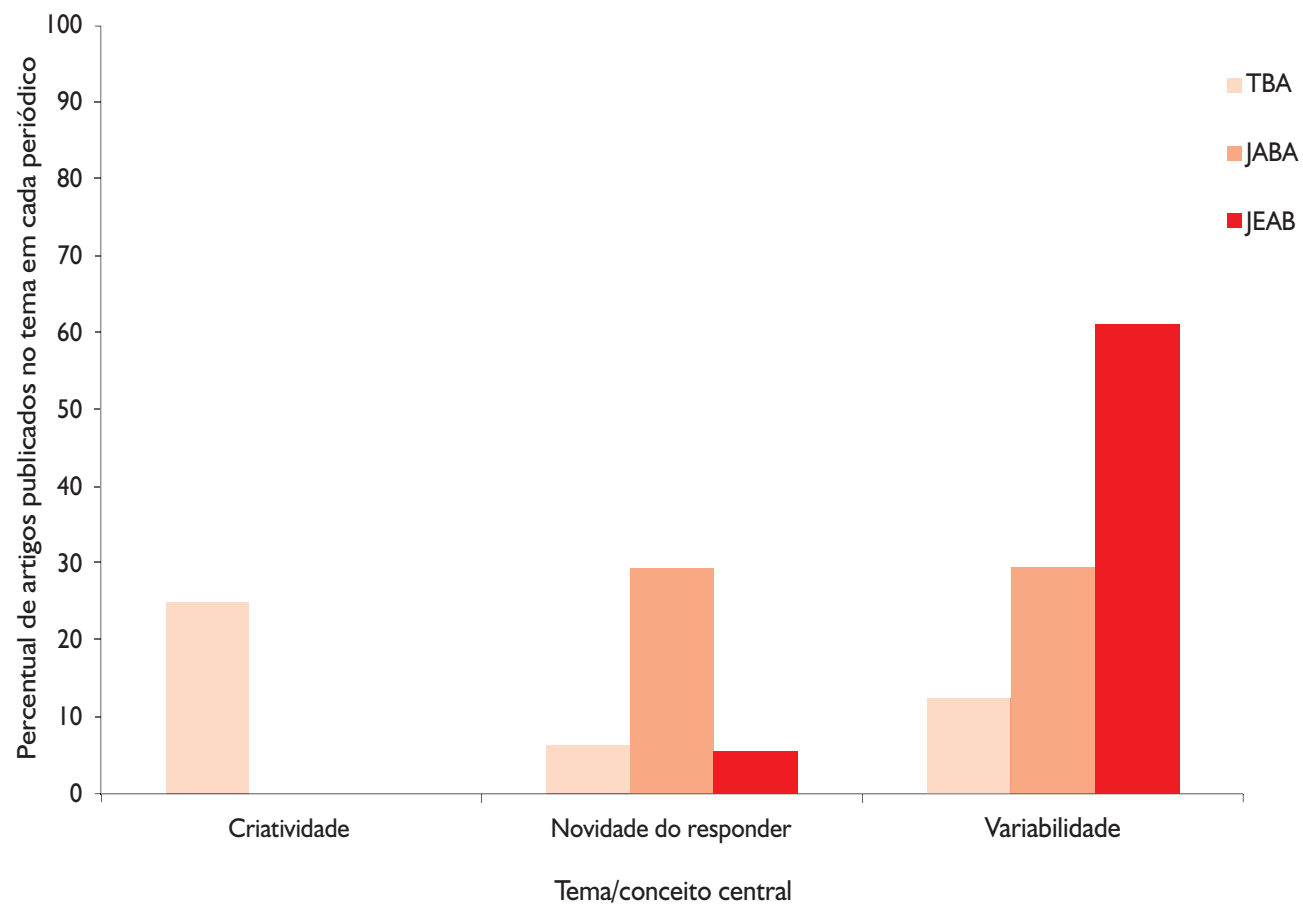

Nota: Nesse gráfico, foram inseridos apenas os temas/conceitos que apresentaram mais que $25 \%$ de ocorrências em pelo menos um periódico (pelo menos quatro estudos no mesmo periódico).

Fonte: Elaborado pelos autores.

Não se sugere, com isso, que os autores do Jeab, por exemplo, simplesmente substituíram o termo "criatividade" ou "comportamento criativo" por "variabilidade", mas sim que seus trabalhos são, na realidade, estudos sobre variabilidade, e que muito provavelmente relacionam suas descobertas com o comportamento criativo em algum momento do artigo, dada a importância do conceito de variabilidade para o entendimento da criatividade (Abreu-Rodrigues, 2005; Murari \& Henklain, 2013). Tal relação nem sempre foi estabelecida, visto que 1994 artigos foram encontrados na busca ini- 
cial com o termo "variabilidade", e não necessariamente relacionavam suas discussões com o problema da criatividade. Deve ser considerado o fato de que, no presente estudo, isso ocorreu com artigos que passaram por três critérios de inclusão e quatro de exclusão para que fossem considerados trabalhos relacionados ao comportamento criativo. Além disso, foram encontrados utilizando creative como palavra-chave.

O mesmo se pode dizer dos trabalhos aplicados que, ao definirem novidade no responder como critério para que as respostas de seus participantes produzissem ou não reforço ou ao definirem tal novidade como medida de sua intervenção, utilizaram com maior frequência esse termo e acabaram por não ser agrupados aos trabalhos cujo tema central era a criatividade. Esse aspecto se relaciona com a discussão de que novidade compõe a definição de comportamento criativo, mas é insuficiente para defini-lo (Winston \& Baker, 1985; Souza \& Kubo, 2010).

\section{Gráfico 3. Número acumulado de trabalhos por ano com os termos/conceitos variabilidade, novidade do responder e criatividade}

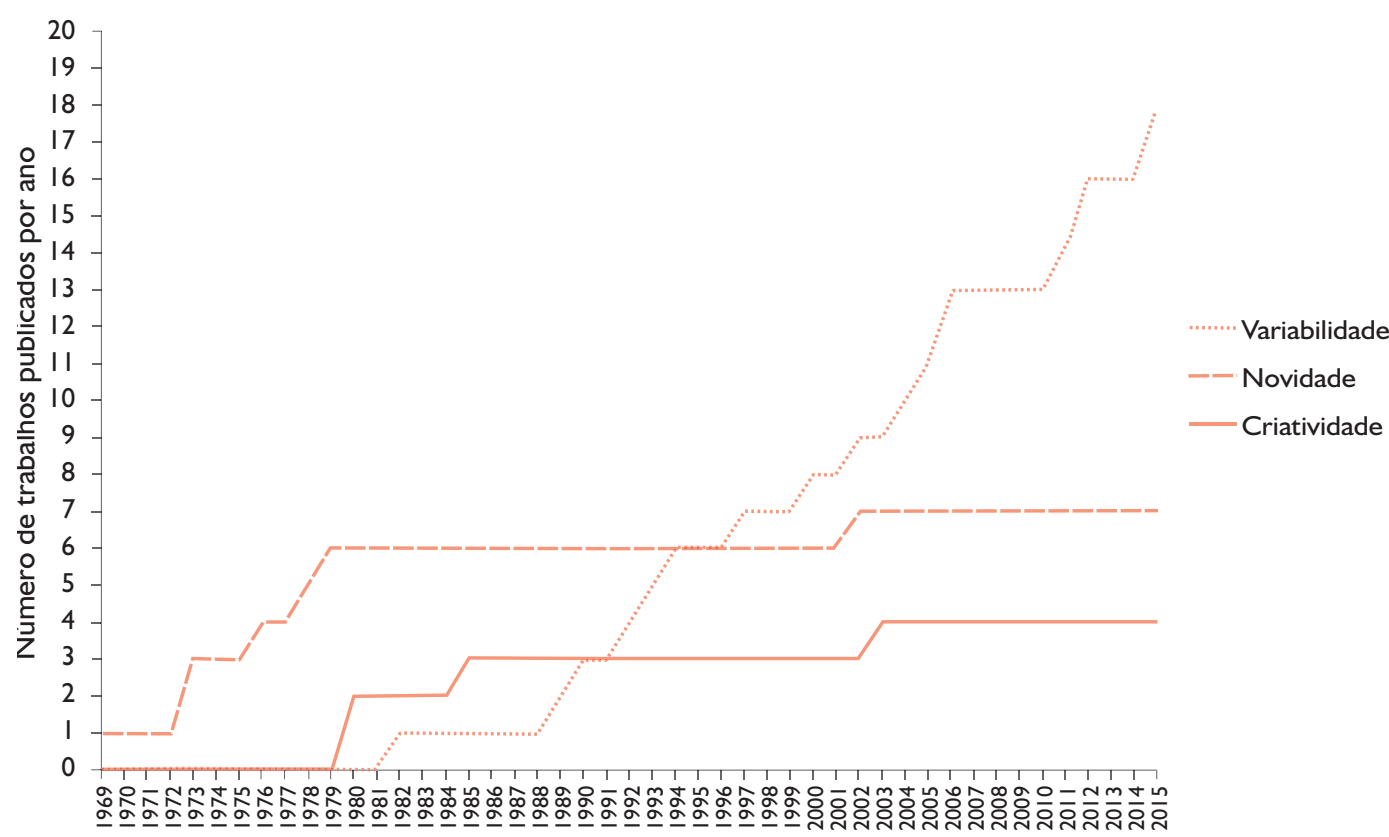

Ano

Fonte: Elaborado pelos autores.

Analisando os dados apresentados no Gráfico 3, que nos apresenta o desenvolvimento do uso dos três termos a cada ano, notamos que "novidade do responder" foi usado com exclusividade na década de 1969 a 1979, coincide com a maior publicação da revista Jaba e, no ano final desta década, com publicações do TBA (Gráfico 1), praticamente caindo em desuso depois desse período. O termo "criatividade" foi usado 
exclusivamente pala revista TBA (Gráfico 2) e com emprego mais frequente entre os anos 1979 e 1985. Posteriormente a 1988, "variabilidade" é o termo/conceito que tem aumentado de frequência ao longo do tempo. Dessa forma, podemos levantar a hipótese de que não se trata apenas de diferentes formas de se referir ao tema na pesquisa teórica, aplicada e básica, mas sim de comportamentos dos pesquisadores que aparentam estar se modificando ao longo do tempo.

Uma análise qualitativa dos artigos de pesquisas empíricas (básica e aplicada) também revelou um aspecto importante: a pesquisa básica esteve mais direcionada para áreas relacionadas ao comportamento criativo, embora não tratasse diretamente do tema, enquanto na pesquisa aplicada observou-se maior centralidade do comportamento criativo nos estudos, o que é condizente com os dados apresentados anteriormente.

Dada essa particularidade na pesquisa aplicada, a análise de algumas de suas características foi realizada. As pesquisas foram feitas com crianças em aproximadamente $79 \%$ dos casos, cerca de $50 \%$ do total de participantes crianças com desenvolvimento típico e $29 \%$ com desenvolvimento atípico. Os demais participantes são jovens e/ou adultos. Em $43 \%$ dos casos, as pesquisas ocorreram no setting escolar, mas foram identificadas também pesquisas realizadas em salas experimentais, residência do participante, academia desportiva e ambiente virtual, além de settings não relatados. No que se refere a respostas-alvo, aproximadamente $31 \%$ investigaram variações no escrever, $16 \%$, em verbalizações vocais e $16 \%$, variações em jogar no computador. Manipulação de brinquedos, improviso de ferramentas, montagem de blocos, e soletrar foram outras respostas-alvo nos estudos, aproximadamente $8 \%$ cada uma. No setting esportivo, a variação na resposta de "golpear em artes marciais" foi alvo de intervenção com participantes adultos.

Esses dados revelam que novos espaços de inserção do analista do comportamento e variedade de respostas-alvo para a pesquisa na abordagem estão surgindo na investigação do fazer criativo quando comparados aos dados de Winston \& Baker (1985). Além disso, a maioria das respostas investigadas têm relevância social, ao menos na comunidade particular a que se referem os estudos, como é o caso da resposta de "escrever", de especial interesse no ambiente escolar, o que indica uma preocupação empírica dos autores da abordagem com o educar para o criar (Murari \& Henklain, 2013). Estudos futuros que investiguem os processos que aumentam a probabilidade de comportamento novo, potencialmente criativo, também podem fazê-lo utilizando outras respostas das quais é socialmente exigida originalidade.

Uma consideração a se fazer é a de que, como abordado por Skinner (1968) em nossa cultura há o mito de que o ensino tolhe a criatividade, porque a mente é preenchida com ensinamentos e nenhum espaço restaria para novas ideias. Resultados de ensino por condicionamento operante direto obtidos com crianças em fase de formação escolar como os que foram analisados são valiosos também por questionar essa crença. Além disso, tais resultados corroboram os postulados de que comportamento criativo pode ser ensinado, não é exclusivo de alguns indivíduos (Skinner, 1968; 1972; 
Epstein, 1980) e desconstroem a crítica de que a posição behaviorista radical não estaria apta a lidar com o fenômeno (Skinner, 1974).

Além das características dos participantes, settings e respostas-alvo dos estudos, a análise das medidas utilizadas para se dizer se o comportamento ensinado tornou-se ou não mais criativo também pode ser de especial interesse se estivermos preocupados em analisar a produção da área e atentar para os elementos que podem definir comportamento criativo na abordagem.

\section{Gráfico 4. Percentual de artigos da amostra publicados na pesquisa aplicada por medidas de criatividade adotadas}

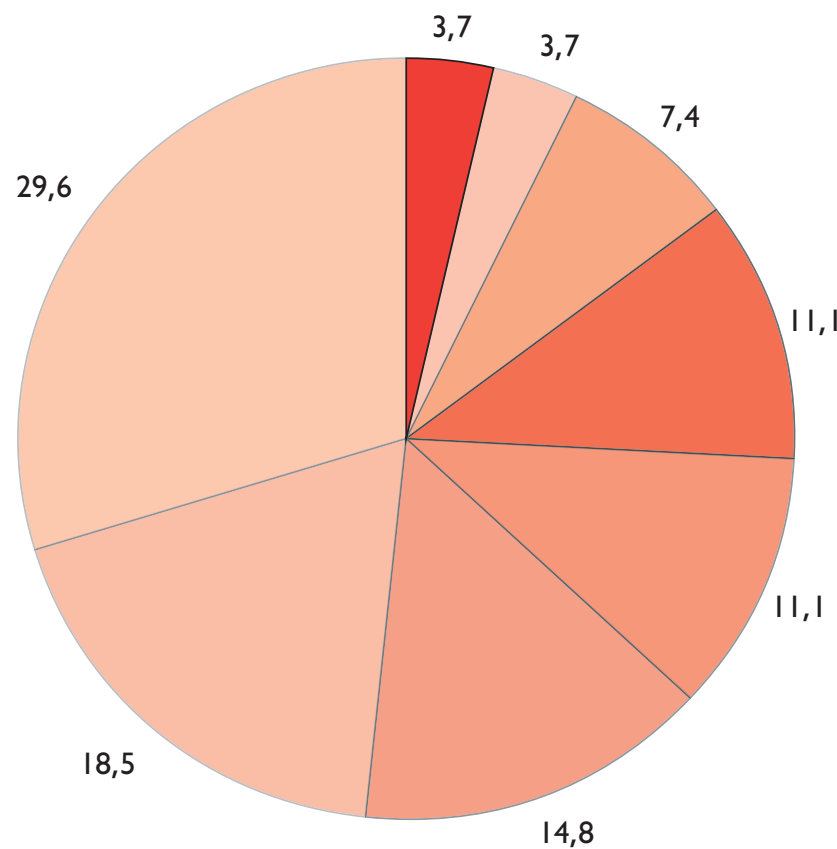

Novidade do produto da $R$

Complexidade da R (composta por diferentes dimensões

Avaliação subjetiva independente

Aumento na quantidade do responder

Variação no responder

Teste de Criatividade de Torrance

Sensibilidade às contigências e controle por regra

Novidade/originalidade do responder

Fonte: Elaborado pelos autores.

No Gráfico 4, que apresenta os dados referentes às medidas de criatividade usadas pelos pesquisadores, observa-se que $29,6 \%$ dos estudos investigaram respostas complexas e avaliaram suas diferentes dimensões como diversidade, fluidez, flexibilidade, entre outras; $18,5 \%$ avaliaram a novidade/originalidade do responder; $14,8 \%$, a variação do responder e $11,1 \%$, o aumento na quantidade do responder. Todos esses estudos centraram-se na novidade da resposta e/ou suas propriedades, se considerarmos a definição do comportamento criativo utilizando a tríplice contingência, não abarcando a segunda definição de criatividade sistematizada por Souza e Kubo (2010) envolvendo a emissão de respostas conhecidas diante de estímulos novos. 
No que diz respeito às consequências do responder e, portanto, aos critérios e referentes de comparação da comunidade para considerar o comportamento como criativo (Skinner, 1968; Hunziker, 2006; Bandini \& de Rose, 2006), alguns estudos utilizaram procedimentos de avaliação independente como medida de criatividade: 11,1\% utilizaram "avaliação subjetiva independente" ou validação social (Winston \& Baker, 1985), 3,7\% atentaram para a novidade do produto da resposta e 7,4\% aplicaram os testes padronizados de criatividade de Torrance.

Não foram encontrados estudos na amostra que analisassem o papel de comportamentos precorrentes no comportamento criativo, de modo a contemplar a definição de comportamento criativo como solucionador de problemas fornecida por Skinner (1968; 1953).

\section{Conclusões}

A presente pesquisa buscou analisar estudos relativos ao comportamento criativo em três periódicos internacionais de Análise do Comportamento, caracterizando esses trabalhos e levantando hipóteses para o comportamento de seus autores. A partir da metodologia de pesquisa adotada e análise dos resultados obtidos, pudemos chegar a algumas conclusões.

Os resultados gerais da busca inicial e os procedimentos de inclusão e exclusão amostral apontaram na direção de que a utilização de termos relacionados à criatividade pelos pesquisadores nem sempre acompanhou o interesse específico no estudo desse fenômeno, podendo estar presentes em artigos na forma como são utilizados no senso comum (ver critérios de exclusão). Pesquisas futuras poderiam investigar quais são as variáveis controladoras do comportamento verbal dos autores ao usarem o termo "criativo" para qualificar pessoas, trabalhos, procedimentos, resultados etc. Em outras palavras, trata-se de responder às perguntas: Por que diante de tais eventos e não de outros se diz que os mesmos são criativos? Trata-se de respostas conhecidas diante de contextos novos? De topografias discretamente diferentes das comumente observadas na área? Ou de resultados valiosos e inusitados para a comunidade do autor? Este seria um estudo interessante no sentido de apontar as variáveis controladoras do tato "criativo".

Também identificamos como contribuição do presente estudo, a verificação da necessidade de testar empiricamente se o aumento na variabilidade do responder produzido pelas pesquisas mais recentes correspondem necessariamente ao aumento nos julgamentos de criatividade por validação social, medida utilizada por estudos mais antigos na área, e progressivamente abandonada. Tal contribuição recorreu à definição de comportamento criativo tomada no presente estudo, que considera, além das respostas novas, o referente cultural de análise para dizer que um comportamento é criativo, especialmente original e útil para uma comunidade (Bandini \& de Rose, 2006; Souza \& Kubo, 2010). 
Outra contribuição consiste na observação de que esses estudos não têm considerado a interpretação do comportamento criativo feita por Skinner (1953; 1968) como um comportamento solucionador de problema, também discutida por Murari e Henklain (2013). Nessa interpretação é o próprio indivíduo que manipula as variáveis que alteraram a probabilidade de outras respostas (novas), potencialmente criativas. Questiona-se se essa possibilidade poderia se dar com o reforçamento direto da variabilidade, uma vez que talvez não haja razões para um indivíduo privar-se de reforços de que dispõe e consumi-los apenas quando observasse variação em seu responder. A possibilidade de auto-observação de variações no próprio comportamento com este refinamento também precisa ser discutida pela literatura.

Dessa afirmação, decorre que pelo menos dois tipos de pesquisa do comportamento criativo fazem-se possíveis e necessárias: aquelas nas quais o pesquisador altera diretamente a probabilidade do responder novo, como nos estudos sobre variabilidade; e aquelas nas quais o pesquisador ensina comportamentos que seus participantes ou sujeitos possam emitir com a finalidade de alterar a probabilidade do responder novo, o que não foi encontrado na amostra do presente trabalho. De cada um desses dois tipos de pesquisa, decorrem possibilidades tecnológicas diferenciadas.

Apesar de serem coerentes com as discussões defendidas na literatura da área, as interpretações do presente trabalho poderiam ser corroboradas por estudos futuros que preencham lacunas deixadas, uma vez que a amostragem e a classificação dos artigos podem produzir vieses que limitam interpretações mais categóricas. Além disso, a identificação das contingências que controlaram o comportamento dos estudiosos (Andery, Micheletto, \& Sério, 2000) é uma tarefa que deve ser completada por mais de uma pesquisa histórica, em razão sua dificuldade, exatamente pelo fato de muitas dessas contingências não estarem mais em vigor e terem se perdido ao longo da história da área, tal como ocorre na análise do comportamento individual quando perseguimos as contingências que deram origem a um comportamento, mais difíceis de identificar do que aquelas que o mantém.

\section{Referências}

Abreu-Rodrigues, J. (2005). Variabilidade comportamental. In J. Abreu-Rodrigues, M. R. \& Ribeiro (Orgs.). Análise do comportamento - pesquisa, teoria e aplicação (pp. 189-210). Porto Alegre: Artmed.

Andery, M. A. P. A., Micheletto, N., \& Sério, T. M. A. P. (2000). Pesquisa histórica em análise do comportamento. Temas em Psicologia, 8(2), 137-142.

Bandini, C. S. M., \& De Rose, J. C. C. (2006). A abordagem behaviorista do comportamento novo. Santo André: ESETec.

Barbosa, J. I. C. (2003). A criatividade sob o enfoque da análise do comportamento. Revista Brasileira de Terapia Comportamental e Cognitiva, 5(2), 185-193. 
Delage, P. E. G., \& Carvalho Neto, M. B. (2006). Comportamento criativo e análise do comportamento II: Insight. In H. J. Guilhardi, \& N. C. Aguirre (Orgs.). Sobre comportamento e cognição: expondo a variabilidade (pp. 345-351). Santo André: ESETec.

Epstein, R. (1980). Defining creativity. The Behavior Analyst, 3(2), 65.

Epstein, R. (1991). Skinner, creativity, and the problem of spontaneous behavior. Psychological Science, 2(6), 362-370.

Epstein, R. (1996). Cognition, creativity and behavior: selected essays. Westport: Praeger.

Figueiredo, G. M. (2014). Variabilidade comportamental em humanos: uma revisão de estudos publicados em periódicos. Dissertação de mestrado, Pontifícia Universidade Católica de São Paulo, São Paulo, SP, Brasil.

Hunziker, M. H. L. (2006). Comportamento criativo e Análise do Comportamento I: variabilidade comportamental. In H. J. Guilhardi, \& N. C. Aguirre (Orgs.). Sobre Comportamento e Cognição: Expondo a Variabilidade (pp. 156-165). Santo André: ESETec.

Laurenti, C. (2009). Criatividade, liberdade e dignidade: impactos do darwinismo no Behaviorismo Radical. Scientia e studia. São Paulo, 7(2), 251-269. DOI: http://dx. doi.org/10.1590/S1678-31662009000200006.

Murari, S. C., \& Henklain, M. H. O. (2013). Criatividade em debate: algumas contribuições da análise do comportamento. Temas em Psicologia, 21(1), 17-29. DOI: https://dx.doi.org/10.9788/TP2013.1-02.

Neuringer, A. (2002). Operant variability: evidence, functions, and theory. Psychonomic Bulletin \& Review, 9(4), 672-705.

Pryor, K. W., Haag, R., \& O'Reilly, J. (1969). The creative porpoise: training for novel behavior. Journal of the Experimental Analysis of Behavior, 12(4), 653661. DOI: 10.1901/jeab.1969.12-653.

Sério, T. M. A. P., Andery, M. A. P. A., Gioia, P. S., \& Micheletto, N. (2002). Controle de estímulos e comportamento operante. Uma (nova) introdução (3a ed. rev.). São Paulo: Educ, 2010.

Shahan, T. A., \& Chase, P. N. (2002). Novelty, stimulus control and variability. The Behavior Analyst, 25(2), 175-190.

Skinner, B. F. (1953). Ciência e comportamento humano (11a ed.). São Paulo: Martins Fontes, 2003.

Skinner, B. F. (1968). O estudante criativo. In B. F. Skinner. Tecnologia do ensino (pp.159-173). São Paulo: EPU, 1972.

Skinner, B. F. (1972). Creating the creative artist. In J. S. Vargas (Org.) Cumulative Record: definitive edition (pp. 379-389). Acton: Copley Publishing Group, 1999. 
Skinner, B. F. (1974). Sobre o Behaviorismo (10a ed.). São Paulo: Cultrix, 2006.

Sloane, H. N., Endo, G. T., \& Della-Piana, G. M. (1980). Creative Behavior. The Behavior analyst, 3(1), 11-21.

Souza, E. J., \& Kubo, O. M. (2010). Características dos componentes da classe geral denominada comportamento criativo identificadas a partir da literatura da análise do comportamento. Acta Comportamentalia, 18(1), 107-134.

Winston, A. S., \& Baker, J. E. (1985). Behavior analytic studies of creativity: a critical review. the Behavior analyst, 8(2), 191-205.

Submissão: 19.3.2015

Aceitação: 15.3.2016 